\title{
Modelling of Electricity Mix in Temporal Differentiated Life-Cycle-Assessment to Minimize Carbon Footprint of a Cloud Computing Service
}

\author{
Elsa Maurice, Thomas Dandres and \\ Réjean Samson \\ École Polytechnique de Montréal \\ CIRODD \\ Montréal, Canada \\ elsa.maurice@gmail.com
}

\author{
Reza Farrahi Moghaddam, Kim \\ Khoa Nguyen and Mohamed Cheriet \\ École de technologie supérieure \\ Synchromedia \\ CIRODD \\ Montréal, Canada
}

\author{
Yves Lemieux \\ Ericsson Canada Inc. \\ Montréal, Canada
}

\begin{abstract}
The information and communications technologies (ICT) sector is seeking to reduce the electricity consumption of data processing centres. Among the initiatives to improve energy efficiency is the shift to cloud computing technology. Thanks to very favourable geographical conditions, the Canadian energy mix is highly suited to the implementation of data centres, especially in light of the significant potential of renewable energy, which can help to curb greenhouse gas emissions. In the green sustainable Telco cloud (GSTC) project, an efficient cloud computing network would be set up to optimize renewable energy use based on several data centres. This study aimed to develop a temporally differentiated life cycle assessment (LCA) model, adapted to short-term predictions, to provide a regionalized inventory to model electricity generation. Purpose of this model is (i) to calculate more accurately the carbon emissions of ICT systems and (ii) to minimize the daily carbon emissions of the GSTC servers. This paper focuses mainly on the electricity generation modelling during the use phase in the context of the life cycle assessment methodology. Considering the time scale of the model, the difference between the annual fixed average and a shorter period may be highly relevant, in particular when assessing the green house gases (GHG) emissions of a process such as an ICT system, which mainly operates during peak load hours. The time dependent grid mix modelling makes it possible to manage the server load migrations between data centres on an hourly basis.
\end{abstract}

Index Terms-Life cycle assessment, data centre, carbon footprint, dynamic power mix.

\section{INTRODUCTION}

\section{A. Information and Communications Technologies: General Context}

In recent years, information and communications technologies (ICT) have grown exponentially. Internet use has exploded in the past decade with the appearance of several social networking services such as Facebook and Twitter and the democratization of video hosting services such as YouTube. Similarly, the more widespread use of mobile devices such as smartphones further increases the use of Internet and causes data flows [1]. The first global system for mobile (GSM) appeared in 1991 in Finland to reach over 5 billions subscribers in 2010 [2]. Quickly evolving networks, devices and computer technologies started to constitute real challenges for the ICT sector from an economical and a technical standpoints [2]. In fact, every 18 months, the processing power of a central processing unit (CPU) and the capacity of mass storage devices approximately doubles [3], increasing their electricity consumption.

Several theories have been set out to predict ICT growth, including Moores' laws, which attempts to guide and plan long-term development, following computer power (processing speed, capacity) [4].

A large number of studies have noted this increase in consumption [5, 6]. In 2007, Ericsson's white paper revealed that mobile telecommunications were responsible for about $0.12 \%$ of global primary energy use [7]. In 2008, in the USA, the electricity consumption of data centres accounted for $2 \%$ of total electricity use [8]. Each year, electrical power plants provide roughly 180 billion $\mathrm{kWh}$ to server farms, making the ICT sector responsible for over $1 \%$ of the world's total electricity consumption [2].

Of all the ICT resources, data centre power consumption is the most significant and it is growing fast [8]. Data centres house several thousand servers with very different power consumptions depending on their use (from a few kilowatts $(\mathrm{kW})$ to hundreds of megawatts (MW)). A significant amount of energy is consumed during their use phase, especially to cool the equipment and power the servers [9]. In 2008, the average worldwide power consumption for data centres was 29 GW[10]. Data centre energy consumption significantly contributes to the environmental impacts of ICT, which represented 2\% of greenhouse gas (GHG) emissions in 2006 $[11,12]$. Despite the massive carbon emissions generated by the development of the ICT sector, in 2006-2007, technology advancement and the increased environmental and social accountability of telecoms slowed the growth [8]. Between 2005 and 2010, the ICT sector only grew by 56\% (instead of 
doubling) due to the economic crisis, improved efficiency and technological advances.

\section{B. ICT Challenges and Progress}

Several challenges must be met in order to reduce the environmental impacts of the ICT sector. The leading issues will be to reduce the energy consumption of data centres and decrease the carbon intensity of the power sources supplying them [13]. Early in 2006, the data centre industry began to focus on solutions and to improve its energy consumption while maintaining an healthy growth [8, 14].

Among the possible solutions, virtualization appears promising. Indeed, data centres tend to be gargantuan enterprises, and virtualization makes it possible to concentrate the loads of multiple virtual machines on a single physical machine. Virtualization therefore enables data centre managers to put unused servers in low consumption mode and save energy. Moreover, virtualization improves the energy efficiency of the server by redirecting the load and optimising the workload. The US-EPA determined that virtualization is effective to reduce the electricity consumption of a server by lowering its contribution from $43 \%$ without virtualization to $27 \%$ with virtualization [9] [15].

Cloud computing can drastically reduce the electricity consumption of infrastructure use compared to private or inhouse data centres [16]. Internet and telephone service providers have adopted the widespread use of cloud computing [17], which relies on virtualization to decentralize an organization's computer resources. In addition, cloudcomputing services improve real-time orchestration and response time and provide shared services [17, 18]. Virtualization and cloud computing technologies can increase storage capacity and support the implementation of powerful hardware, software and real-time communications networks [19]. More and more companies are upgrading their systems to cloud computing in an effort to offer faster download times and more applications [20]. This decentralization moves easier ICT infrastructures towards strategic low-demand and sustainable electricity sources. In fact, big data centres may be built in regions with strong energy assets such hydro, wind or solar power [21]. Server farms can move to countries with more attractive sustainable resources and/or particular climate condition allowing free cooling, such as Sweden or Finland [21]. The free cooling and effective locations have boosted energy efficiency.

All of these measures are part of the drive to design a smart ICT network and pursue the efforts to decrease energy consumption. Smart grid ICT networks aim to manage more efficiently the electric network and integrate renewable energies. While increased energy efficiency has been beneficial, the issue of energy sources has not been resolved at the global level. In fact, at world scale, the primary energy source remains fossil fuels, which emits large amounts of GHG [22, 23]. Telecom industries promoted the use of local existing renewable energy resources instead of fossil fuels to achieve carbon emissions reductions of ICT systems [24]. Nevertheless, the global electric grid mix must be considered to achieve carbon emissions reductions. Indeed, except if the renewable sources are built specifically to supply new ICT systems, the use of existing renewable energy source is not enough to mitigate the climate change. Indeed, (i) reducing energy consumption, (ii) increasing the contribution of renewable energy to the global electricity grid mix and (iii) increasing carbon sequestration can only achieve reduction of GHG emissions. To summarize, three parameters may influence the impact of energy reductions and GHG emissions of a data centre [25]:

- Location (related to its electric grid mix and climate conditions)

- IT workload

- Electricity management

\section{Impact Assessment}

Life cycle assessment (LCA) was invented around 1970 and is now a broad and evolving tool to more effectively move towards sustainable development [26]. LCA evaluates the potential environmental impacts of a product or service throughout its entire life cycle. In certain cases, the implementation of a new technology leads to environmental displacements. For instance, electric cars were designed to reduce GHG emissions in the transport sector and decrease oil dependency. However, while electric engines do not emit GHG during their use phase, the electricity used to recharge the electric batteries may be generated from fossil fuel. Therefore, the GHG emissions of an electric car may be not null when the entire life cycle is considered. Life cycle assessment (LCA) is a method able to track environmental impact displacements since it accounts for all the life cycle. Thus, to evaluate cloud computing and virtualization, the life cycle assessment (LCA) methodology seems appropriate since it accounts for all the life cycle stages. LCA makes it possible to evaluate the impacts and determine hot spots in the life cycle of a product or service. The identification of hot spots can guide research on the life cycle stage (materials, processes, etc.), fostering improvement efforts. ICT studies generally include carbon footprint and energy indicators to estimate the environmental impacts [27]. However, other environmental impacts could also be considered: ozone layer depletion, eutrophication, particulate matter emission, etc... Moreover, carbon footprint factor used in study reflect usually only the use phase impact without considering production, or the end of life, despite these life cycle phase can contribute significantly to overall emissions, hence the importance of the life cycle approach. Also these studies are usually based on fixed coefficients not reflecting the reality of the system variability. Indeed, an assessment of smart grid ICT network impacts requires accurate electricity generation monitoring for each electricity source, including time variations. Temporally differentiated LCA is an innovative approach not included in conventional methods to compute ICT carbon footprint.

\section{Electricity in LCA}

Electricity is an important contributor to ICT impacts $[3,8]$, and its evaluation remains complex and challenging to model in LCA because electricity generation and telecommunication services may vary significantly over time. The conventional 
LCA approach does not allow for an accurate electricity generation modelling [28]. The ecoinvent database, one of the most database used in LCA, models electric grid mixes for European countries based on annual data. However, temporal aggregation such as annual averages may lead to high uncertainties when used to model electricity at a given time, especially due to the high degree of variation in electricity generation at each hour of the day [29]. Consequently, carbon footprint varies over time and space depending on the power generation assets that supply the demand. These variations may significantly affect the carbon footprint of one $\mathrm{kWh}$ [30]. An average approach for electricity generation modelling is correct in LCA when the power demand of the studied process is constant over time. However, many processes like ICT services, consume electricity irregularly. For instance, the Internet use is variable over a day, or maintenance activities like upgrades that are may be done once a day. In addition, often in LCA, the data used to model electricity generation do not correspond to the region in which the electricity is actually consumed. Indeed, ecoinvent is known for the quality of its data, but the database assumes that all processes occur in Europe. Thus, electricity generation in Ecoinvent only reflects the European reality. For this reason, many authors are turning towards national data of annual electricity production mixes based on the context of their studies [27, 31]. Institutions such as the World Resources Institute (WRI) and the United States Environmental Protection Agency have set up national and sub-national electricity mixes to calculate the impacts of electricity generation. However, modelling of a time dependent electricity generation is still absent in the guidelines of environmental impacts assessment.

Therefore there is a need to disaggregate the temporal dimension of electricity modelling in LCA in order to adequately evaluate ICT systems. This disaggregation implies the use of accurate data to model an hourly electricity generation. Moreover, these data must reflect the reality of the region in which the electricity is generated.

In this paper, a regional temporally differentiated electricity model is proposed for LCA to model temporal fluctuation of the environmental impacts. This paper focuses mainly on the electricity generation modelling during the use phase of ICT systems in the context of the LCA methodology.

The model provides a regionalized inventory of electricity generation to (i) calculate carbon emissions and other environmental impacts more accurately than with conventional LCA approach and (ii) minimize the daily emissions of the servers of the green sustainable Telco cloud (GSTC) by optimizing the management of the daily workload of the servers. One of the purposes of the GSTC project is to set up an efficient data centre network to optimize renewable energy use by using different server nodes located at different places and relying on different sources of electricity. Workload migrations between server nodes are managed to minimize the GSTC carbon footprint.

\section{MATERIALS AND METHODS}

\section{A. Life Cycle Assessment}

A life cycle may be divided into four steps: extraction of raw materials, component manufacturing, use phase and endof-life (Fig 1).

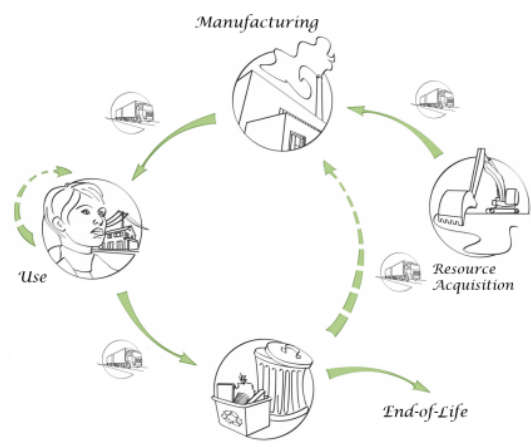

Fig. 1. Life cycle phases (www.ciraig.org @ 2008 , reproduced with permission of the CIRAIG)

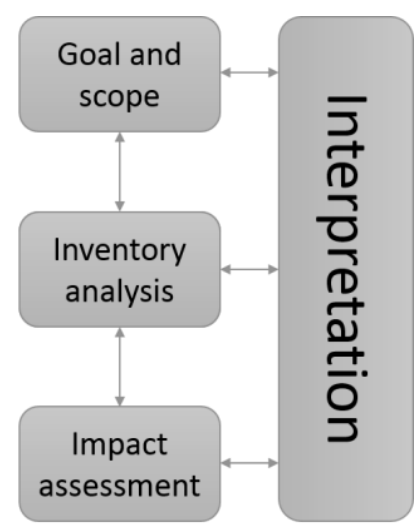

Fig. 2. LCA phases (www.ciraig.org @ 2008, reproduced with permission of the CIRAIG)

The first step is the acquisition of the raw materials required for the production. The second step involves all the manufacturing processes, including assembly and packaging.

The third step is the use phase in which the product is consumed and may require additional flows such as electricity, or actions like maintenance, washing, etc. The end-of-life is the step in which the product is land filled, incinerated, recycled or reused. There is also transport in or between each phase.

Since 2006, LCA has been guided by a series of standards set out by the International Organization for Standardization (ISO). The principles and framework of LCA are described in ISO standards 14040 and 14044, which detail the four phases of an LCA: definition of the goal and scope of the study, life cycle inventory analysis (LCI), life cycle impact assessment (LCIA) and life cycle interpretation (Fig 2).

The first phase aims to define the goal of the study and the conditions under which it is conducted. Several parameters must be defined in this phase: the function of the product or 
service, the functional unit to compare different products and the limitations generated by the system boundaries and assumptions.

In the second phase, the substances extracted from the environment or emitted to the environment by every process in each step in the life cycle are listed.

The different material and energy flows are determined in order to fit with the functional unit. The result is a list of thousands of substances quantities. The inventory stage may yield a succinct preliminary interpretation. This stage is important to describe correctly all LCA processes and validate the accuracy of the system. An aggregation of data is usually necessary to facilitate data collection. The complexity of data collection is a critical point of a large number of LCA studies.

In the third phase, the potential environmental impacts are calculated based on the results of the inventory phase. The impacts depend on the harmful substances and types of resources involved and their quantities. There are several methods based on different assumptions to model the causeeffect chain. Resource requirements and emissions during the life cycle are gathered into several environmental impacts categories. Characterization factors are applied to inventory data. Impact assessment makes it possible to aggregate thousands of substances from the LCI into a small number of environmental impacts. Two levels of aggregation may be used: the midpoint level involves a few dozen impact categories, and the endpoint level stops later in the causeeffect chain and includes only four, more intuitive, impact categories: human health, ecosystem, climate change and resources.

Finally, in the fourth phase, the results are discussed based on the assumptions, boundaries and limitations of the study. During this stage, sensitivity and uncertainty analyses are carried out [32]. Uncertainties are to be checked carefully in order to validate future predictions in LCA.

\section{B. Case Study}

The methodology was developed through a GSTC case study that focused on only one data centre in Ontario. The objective of this case study is to minimize the daily GHG emissions of a data centre by managing punctual workloads depending on the hourly electric grid mix supplying the data centre. The punctual workload is not precisely defined but it could be related to server maintenance activities like upgrades, backup, system scan, etc... It is assumed this maintenance activity would result in an increase during two hours of $1 \mathrm{MW}$ in the power demand of the data centre (total capacity being 100 MW). Three models of electricity generation are compared:

- Conventional LCA

- Temporally differentiated LCA model

- Historical model

Each model is used in an equation to evaluate the carbon footprint related to electricity consumption (Eq.1). The electricity source represents the part of each technology used to supply the power demand. The second term is the power consumption based on the data centre workload. Finally, the emission factor allows to compute the life cycle carbon footprint of each source of electricity throughout its the entire life cycle, from production to end of life. These three models differ in their temporal description of the electricity generation by source, which affects the source percentage, and the data centre electricity consumption, which vary over time. All three models use ecoinvent data but adapted to the Ontario context (Table I). The conventional LCA model uses a grid mix based on the annual average of Ontario electricity generation. The annual average is computed from historic data of electricity generation in Ontario (Eq. 2).

The temporally differentiated LCA model compiles electricity generation data hour by hour. Two sub-models are proposed: the annual one and the monthly one. The difference between the two models differs in the aggregation of data. The annual model is obtained by aggregating hourly data at the annual scale. This results in a grid mix representing an average day at the annual level (Fig. 4). In the monthly model, the aggregation is made at the month level resulting in a daily grid mix for each month (Eq. 3).

Table I. ECOINVENT LIBRARY ELECTRICITY PROCESS

\begin{tabular}{|l|l|}
\hline \multicolumn{1}{|c|}{ Energy source } & \multicolumn{1}{c|}{ Ecoinvent process } \\
\hline \multirow{2}{*}{ Coal } & $\begin{array}{l}\text { Electricity, hard coal, at power plant/NPCC U (Ontario) } \\
\text { Electricity, hard coal, at power plant/WECC U (Alberta) }\end{array}$ \\
\hline Hydro & Electricity, hydropower, at reservoir power plant, non alpine regions/RER U \\
\hline \multirow{2}{*}{ Natural gas } & Electricity, natural gas, at power plant/NPCC U (Ontario) \\
\cline { 2 - 2 } & Electricity, natural gas, at power plant/WECC U (Alberta) \\
\hline Nuclear & Electricity, nuclear, at power plant boiling water reactor/US U \\
\hline Oil & Electricity, oil, at power plant/UCTE U \\
\hline Wind & Electricity, at wind power plant 800kW/RER U \\
\hline
\end{tabular}

\footnotetext{
Carbon footprint $(\mathrm{kgCO} 2 \mathrm{eq})=$

$\sum_{i}$ Electricity source $i(\%) *$ Electricity consumption $(K W h) *$ emission factor $i\left(k g C 02 \frac{e q}{k W h}\right)$
} 
Electricity source $\mathrm{i}(\mathrm{t})=$ Yearly average data

$$
\begin{gathered}
\text { Electricity source: } \\
\text { Nuclear }=x \% \\
\text { Coal }=y \% \\
\text { Natural gas }=z \% \\
\text { Etc... }
\end{gathered}
$$

Electricity consumption $=$ average consumption

(Eq. 2)

Electricity source $i(t)=$ Hourly data per month

Electricity source:

Nuclear $=x$ (month, hour $) \%$

Coal $=y$ (month, hour) \%

Natural gas $=z$ (month, hour) $\%$

Etc...

Electricity consumption $=$ function $($ day, hour $)$

(Eq. 3)

Electricity source i = Hourly data per day

Electricity source:

Nuclear $=x($ day, hour $) \%$

Coal $=y($ day, hour $) \%$

Natural gas $=z$ (day, hour $) \%$

Etc...

Electricity consumption $=$ function $($ day, hour $)$

(Eq. 4)

The historical model reflects the electricity generation hour-by-hour, day-by-day over the defined period (Eq. 4). A specific hourly grid mix represents each day independently.

All data have been collected from Ontario public utilities [33]. Data are available at every hour for every Ontario power station. The raw data for each power station have been aggregated by technology (nuclear, natural gas, etc.). All the electricity sources representative of the Ontario electricity grid mix were computed (nuclear, coal, natural gas, hydro, wind and oil) for every hour between January 2012 and December 2012.

SimaPro LCA software was used with the method IMPACT 2002+ to calculate the emission factors of one $\mathrm{kWh}$ of each technology. This approach can account for 17 impact categories but this paper focuses on climate change damage
Table II. LCA EMISSION FACTORS

\begin{tabular}{|c|c|}
\hline Energy source & $\begin{array}{c}\text { Emission factor } \\
\left(\mathrm{kg} \mathrm{CO}_{2 \mathrm{eq}} / \mathrm{kWh}\right)\end{array}$ \\
\hline Coal & 1.150 \\
\hline Natural gas & 0.693 \\
\hline Nuclear & 0.014 \\
\hline Hydroelectricity & 0.013 \\
\hline Wind & 0.012 \\
\hline Oil & 0.894 \\
\hline
\end{tabular}

assessment only $\left(\mathrm{kg} \mathrm{CO}_{2 \mathrm{eq}}\right.$ ). The results are emission factors per amount of electricity consumed $\left(\mathrm{kg} \quad \mathrm{CO}_{2 \mathrm{eq}} / \mathrm{kWh}\right)$ at different time scales depending on the model:

- Annual average in the conventional LCA model

- Hourly average by month in the temporally differentiated LCA model

- No average for the historic model

Series of calculations of standard derivation have been used to validate temporally differentiated model and observed trends.

\section{RESULTS AND DISCUSSION}

Table II illustrates the life cycle GHG emissions of each technology for $1 \mathrm{kWh}$ of electricity. Table II shows the significant differences in the emission of the source of energy. Electricity from fossil fuels has high emission factors. It is important to note that the emission factors of renewable energy such as hydro and wind are not null since the entire life cycle is taken into consideration and emissions are generated during manufacturing and transport.

The variations in electrical supply sources cause the GHG emission factor to fluctuate dramatically. It goes from 55 to $283 \mathrm{~g} \mathrm{CO}_{2 \text { eq }}$ per $\mathrm{kWh}$ for the historical profile compared to the annual average $300 \mathrm{~g} \mathrm{CO}_{2 \text { eq }}$ per $\mathrm{kWh}$ (Fig.3).

Figure 4 depicts the average daily variation hour by hour of the carbon emission factor per $\mathrm{kWh}$ in Ontario. According to this temporally differentiated LCA model at the annual scale, to reduce the carbon emissions of the data centre, maintenance should be carried out around 3 a.m. (emission factor close to $100 \mathrm{~g} \mathrm{CO}_{2 \mathrm{eq}} / \mathrm{kWh}$ at this time). Also, maintenance should be avoided at peak times (e.g. 7 p.m.) when the emission factor is high (around $180 \mathrm{~g} \mathrm{CO}_{2 \mathrm{eq}} / \mathrm{kWh}$ ).

Figure 5 compares the GHG emissions due to a maintenance activity when applying the conventional LCA model or the annual temporally differentiated LCA model. 


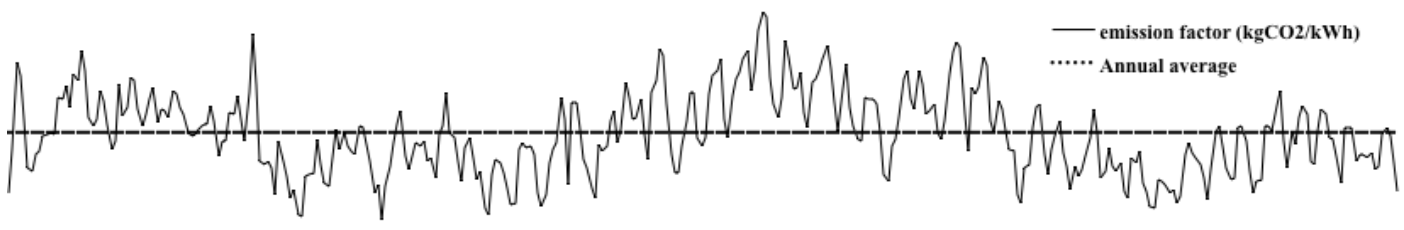

Fig. 3. Ontario emission factor year variation compared to annual average

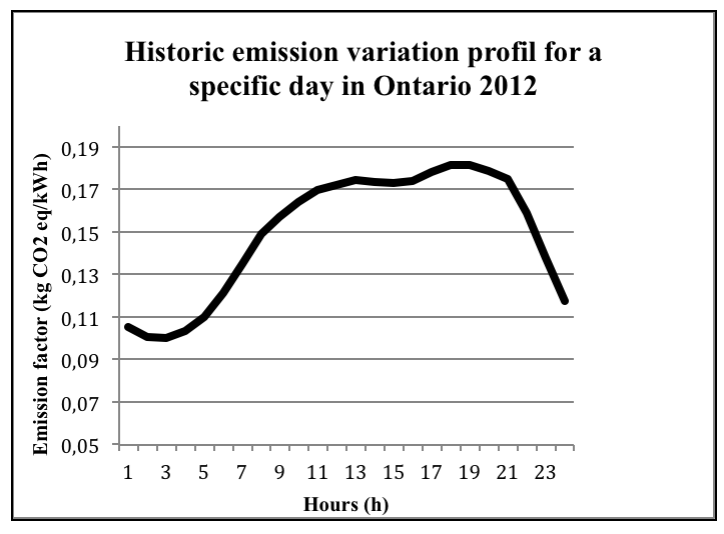

Fig.4. Ontario temporal differentiated LCA model 2012

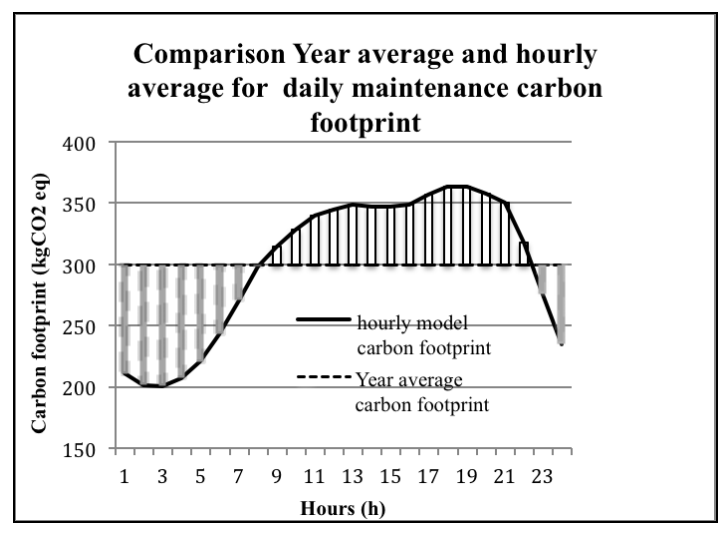

Fig.5. Comparison profile conventional LCA vs. temporal differentiated

Between 10 p.m. and 7 a.m., the carbon footprint of the maintenance is overestimated by $100 \mathrm{~kg} \mathrm{CO}_{2 \mathrm{eq}}$ when using the conventional LCA model compared to the dynamic LCA

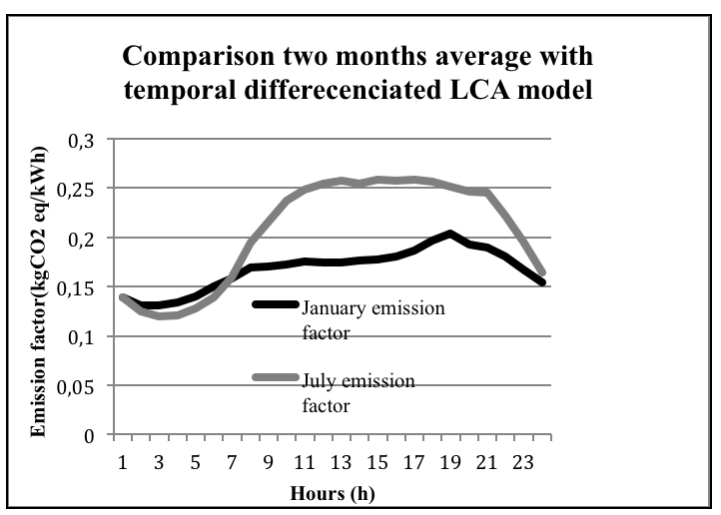

Fig.6. Emission factor for two months in Ontario

model. Furthermore, between 8 a.m. and 9 p.m., the conventional LCA model underestimates the environmental impact of maintenance of about $50 \mathrm{~kg} \mathrm{CO}$ 2eq. This illustrates the importance of using a temporal differentiated LCA model to manage efficiently some occasional tasks of the data centre.

Figure 6 presents the daily average GHG emissions (hour by hour, based on historic data) for both months January and July. It shows, as expected, that months have to be considered separately to improve the accuracy of the temporally differentiated LCA model.

Figure 7 shows Ontario emission factor obtained from the monthly temporally differentiated LCA model.

The gap between minimum and maximum due to hourly variation in electricity supply can be observed for each month on the figure 7. For each month, the hours with the highest and the lowest impact have been identified to manage workload and punctual action such as maintenance. More trends can be observed with summer and winter months, which are more $\mathrm{CO}_{2}$, impacting per $\mathrm{kWh}$. 


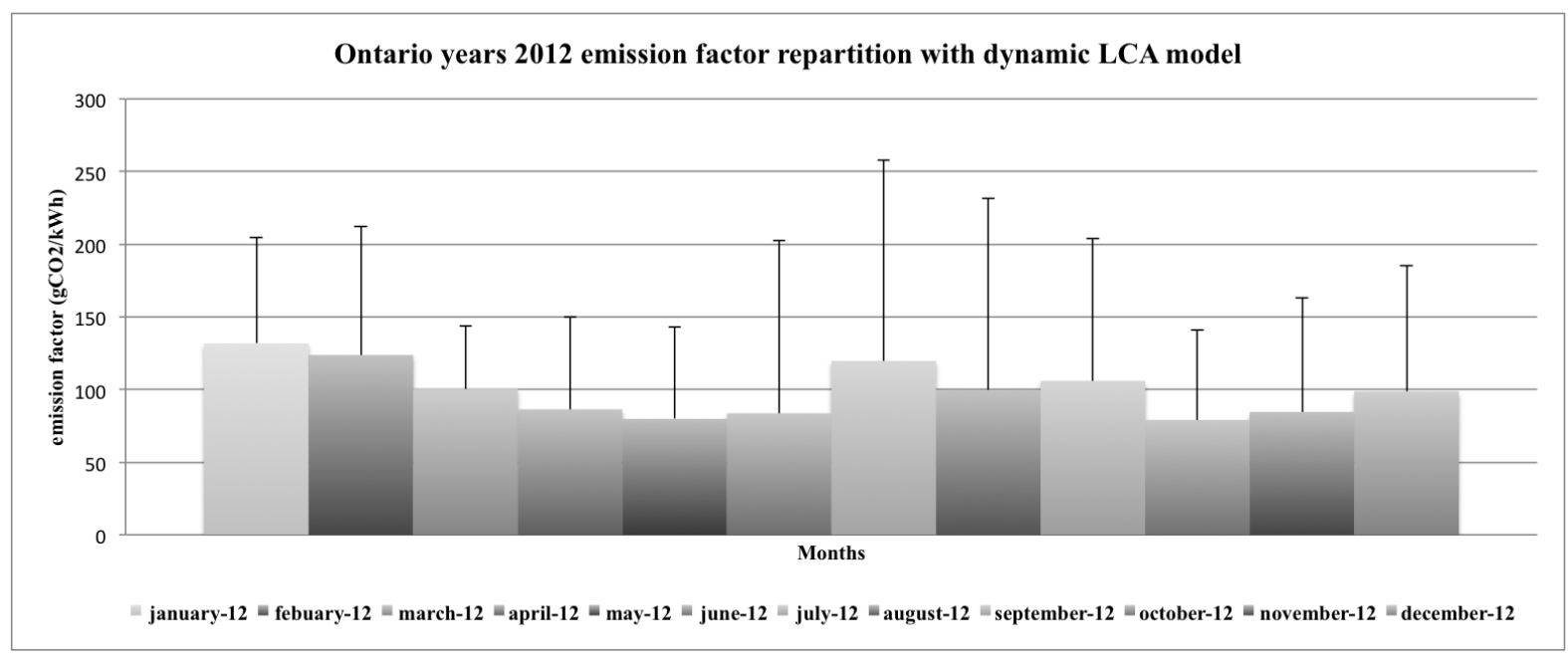

Fig.7. Ontario emission factor from dynamic LCA model

Table III illustrates the variation of the emission factors for the three LCA models over a year. These variations validate the temporally differentiated model, which is closer to the historical reality than the conventional LCA model. It only has a difference of $24 \mathrm{~g} \mathrm{CO}_{2 \mathrm{eq}} / \mathrm{kWh}$ for the lower bound and 25 $\mathrm{g} \mathrm{CO}_{2 \mathrm{eq}} / \mathrm{kWh}$ for the upper bound.

Table III. COMPARISON OF THE EMISSION FACTORS OF THE THREE MODELS

\begin{tabular}{|c|c|c|}
\hline $\begin{array}{c}\text { Conventional LCA } \\
\text { emission factor } \\
\left(\mathrm{g} \mathrm{CO}_{2} / \mathrm{kWh}\right)\end{array}$ & $\begin{array}{c}\text { Temporal } \\
\text { differentiated } \\
\text { historical emission } \\
\text { factor } \\
\left(\mathrm{g} \mathrm{CO}_{2} / \mathrm{kWh}\right)\end{array}$ & $\begin{array}{c}\text { Temporal } \\
\text { differentiated model } \\
\text { emission factor } \\
\left(\mathrm{g} \mathrm{CO}_{2} / \mathrm{kWh}\right)\end{array}$ \\
\hline 150 & $\begin{array}{c}\mathrm{Min}=55 \\
\mathrm{Max}=283\end{array}$ & $\begin{array}{c}\mathrm{Min}=79 \\
\mathrm{Max}=258\end{array}$ \\
\hline
\end{tabular}

The monthly temporally differentiated model allows to reduce significantly the uncertainty related to electricity generation when compared to the conventional LCA model. Standard deviations of the values provided by the temporally differentiated model (hour by hour and month by month) are quite small, the highest observed standard deviations being smaller than $4 \%$ (for the nuclear power).

It was also observed that not all energy sources meet equally the changes in the electrical demand. Some sources have a relatively constant level of charge (cf. Table IV) meaning that they do not adapt their generating capacity when the demand changes. Indeed, the nuclear power response to electrical demand is of only $17.5 \mathrm{MW}$ whereas it goes up to $672 \mathrm{MW}$ for hydro. It can be concluded that electricity sources do not respond in the same way to the variations in demand. This can be explained by the flexibility of the different technologies to change their generating capacity. Hydro and natural gas are well known for their high flexibility while nuclear power is more static and usually used to meet the base load power demand.
The fluctuating power demand is defined as the marginal electricity. The study of marginal electricity could be highly relevant when computing the carbon footprint since hydroelectricity has a very low GHG emission factor. Hydroelectricity decreases the Ontario grid mix GHG emissions when it contributes significantly to the global power generation.

Beyond the variations of the power demand in Ontario, the high standard deviation for hydroelectricity in Table IV could also be explained by the significant export of hydroelectricity to the United States, for economical reasons [34]. To test this assumption, an inter-regional study of the electricity imports and export between Ontario and its neighbours would be required. It is expected Ontario exports electricity to the United States but imports also electricity from the United States and Quebec too. Including these inter-regional flows could affect the emissions related to the electricity consumed in Ontario depending on the sources of electricity involved. Therefore, import and export of electricity should also be considered when minimizing emissions of a data centre in Ontario.

The general results highlight the importance of using a temporally differentiated LCA model to evaluate ICT GHG emissions. The temporally differentiated LCA provides a more accurate GHG emission profile than the conventional LCA. Moreover, considering the electrical demand variations allows to anticipate cyclic trends over months and to choose the best time to plan punctual activities raising the power demand of the data centre. Aggregated results, which are often used in LCA, can be misleading since changes in important factors may be buried in the aggregation process. This is especially true for a process in which electricity demand varies over time. 
Table IV. COMPARISON OF ELECTRICITY OUTPUT TRENDS (2012 DATA)

\begin{tabular}{|c|c|c|c|c|c|c|c|}
\hline Data & $\begin{array}{c}\text { Nuclear } \\
(\mathrm{MW})\end{array}$ & $\begin{array}{c}\text { Coal } \\
(\mathrm{MW})\end{array}$ & $\begin{array}{c}\text { Natural Gas } \\
(\mathrm{MW})\end{array}$ & $\begin{array}{c}\text { Hydro } \\
(\mathrm{MW})\end{array}$ & $\begin{array}{c}\text { Wind } \\
(\mathrm{MW})\end{array}$ & $\begin{array}{c}\text { Oil } \\
(\mathrm{MW})\end{array}$ & $\begin{array}{c}\text { Total output } \\
(\mathrm{MW})\end{array}$ \\
\hline Min output & 9679 & 170 & 1397 & 2573 & 478 & 150 & 14567 \\
\hline Max output & 9737 & 761 & 3288 & 4496 & 568 & 205 & 19001 \\
\hline Annual average & 9715 & 493 & 2537 & 3697 & 531 & 177 & 17149 \\
\hline Standard deviation & 17.5 & 228 & 675 & 672 & 25.9 & 20 & 1594 \\
\hline
\end{tabular}

The monthly temporally differentiated LCA model seems a good step in the carbon footprint computing of a variable system like ICT. The case study of Ontario validates the temporally differentiated approach to improve the computing of the carbon footprint.

To improve this model, the import/export of electricity should be included. This would increase the model accuracy by making a distinction between electricity generated locally versus electricity consumed locally.

The temporally differentiated LCA approach is a part of a better understanding of electrical flow and related impacts. In fact, despite some good improvement from ICT companies, carbon footprint is often partially evaluated in current calculations because of narrow boundaries of the studied systems. In September 2013, Google, as part of their green strategy, purchased the entire electricity production of the Happy Hereford wind farm in Texas to compensate for the increase in their energy demand [34]. The Google initiative can be seen as a step forward to a cleaner carbon footprint, however the issue of impacts displacement must be considered. If Google deprives the regional grid mix of a part of the renewable energy, then the regional electricity providers may have to turn on coal power plant or import electricity from other states to meet the household demand. In this situation, a temporally differentiated model considering marginal electricity would be especially relevant.

\section{CONCLUSION}

The temporal fluctuations of electricity are missing from the methods to compute the carbon footprint. The combination of the cradle to grave perspective of LCA with a temporally differentiated model to compute carbon footprint can deal with this issue as it generates a time-varying GHG emission estimate.

The difference between the time scales (year or month) to model the grid-mix and to assess the related GHG emissions of a smart ICT system that mainly operates during peak load hours is highly relevant... For a good environmental management of punctual activities like maintenance considering the dynamicity of the grid mix is quite profitable.

Trends can be drawn from the historical observation of the electricity flow, thus enhancing the environmental efficiency of workload management by a data centre and workload migration between different data centre. Understanding the interaction between a data centre location and its real time power consumption is essential to reduce GHG emission as the electrical demand during peak hours is often satisfied by using fossil fuel power plants. An investigation of import/export seems also a promising avenue to improve the temporally differentiated model accuracy.

\section{ACKNOWLEDGEMENT}

The authors thank the NSERC of Canada for their financial support under grant CRDPJ 424371-11.

\section{REFERENCES}

W. V. Heddeghem, S. Lambert, B. Lannoo, D. Colle, M. Pickavet, and P. Demeester, "Trends in worldwide ICT electricity consumption from 2007 to 2012," Computer Communications, 2014.

[2] gsma, Available: http://www.gsmworld.com/

[3] G. Fettweis and E. Zimmermann, "ICT energy consumption-trends and challenges," in Proceedings of the 11th International Symposium on Wireless Personal Multimedia Communications, p. 6, 2008.

[4] R. R. Schaller, "Moore's law: past, present and future," Spectrum, IEEE, vol. 34, pp. 52-59, 1997.

[5] J. G. Koomey, "Worldwide electricity used in data centers," Environmental Research Letters, vol. 3, p. 034008, 2008.

[6] R. C. Zuker, G. P. Jenkins, H. Lim, and P. Poirier, Blue Gold, 1984.

[7] Ericsson,"Sustainable energy use in mobile communications," August 2007.

[8] J. G. Koomey, "Growth data center electricity use 2005 to 2010," in Analytics Press, ed, 2011.

[9] ABB, "Infographie: l'impact énergétique des data centers," Available:

http://www.abb.fr/cawp/seitp202/1e9c597bdb2d4513c1257956003 309f0.aspx

[10] M. Pickavet, W. Vereecken, S. Demeyer, P. Audenaert, B. Vermeulen, C. Develder, et al., "Worldwide energy needs for ICT: The rise of power-aware networking," in Advanced Networks and Telecommunication Systems, 2008. ANTS'08. 2nd International Symposium on, pp. 1-3, 2008.

[11] S. Mingay, "Green IT: the new industry shock wave," Gartner RAS Research Note G, vol. 153703, 2007.

[12] Gartner, "Gartner Data Quest," Available: http://www.gartner.com/technology/research/business_leaders.jsp

[13] A. Berl, E. Gelenbe, M. Di Girolamo, G. Giuliani, H. De Meer, M. Q. Dang, et al., "Energy-efficient cloud computing," The Computer Journal, vol. 53, pp. 10451051, 2010.

[14] L. Liu, H. Wang, X. Liu, X. Jin, W. B. He, Q. B. Wang, et al., "GreenCloud: a new architecture for green data center," in Proceedings of the 6th international conference industry session on Autonomic computing and communications industry session, pp. 29-38, 2009. 
[15] U. S. E. P. Agency, "Report to Congress on Server and Data Center Energy Efficiency Public Law 109-431," EPAAugust 2007.

[16] P. Thomond, "The Enabling Technologies of low-carbon economy: A focus on cloud Computing," Enabling technology 2020Febuary 2013.

[17] Ericsson, "The real-time Cloud," February 2014.

[18] K. H. Kim, A. Beloglazov, and R. Buyya, "Power-aware provisioning of cloud resources for real-time services," in Proceedings of the 7th International Workshop on Middleware for Grids, Clouds and e-Science, p. 1, 2009.

[19] J. Baliga, R. W. Ayre, K. Hinton, and R. Tucker, "Green cloud computing: Balancing energy in processing, storage, and transport," Proceedings of the IEEE, vol. 99, pp. 149$167,2011$.

[20] X. Y. Wang, X. J. Liu, L. H. Fan, and X. H. Jia, "A Decentralized Virtual Machine Migration Approach of Data Centers for Cloud Computing," Mathematical Problems in Engineering, 2013.

[21] G. USA, "Google centre de données," Available: http://www.google.com/about/datacenters/index.html

[22] M. P. Mills, "The cloud begins with coal big data, big networks, big infrastructure, and big power," ed: National Mining Assoication \& American Coalition for clean Coal Electricity, 2013.

[23] J. Longwell, E. Rubin, and J. Wilson, "Coal: energy for the future," Progress in Energy and Combustion Science, vol. 21, pp. 269-360, 1995.

[24] M. Ghamkhari and H. Mohsenian-Rad, "Optimal integration of renewable energy resources in data centers with behind-the-meter renewable generator," in Communications (ICC), 2012 IEEE International Conference on, pp. 3340-3344, 2012.
[25] D. Bouley, "Estimation de l'empriente carbone électrique d'un datacenter," Schneider Electric.

[26] W. Klöpffer, "Life cycle assessment," Environmental Science and Pollution Research, vol. 4, pp. 223-228, 1997.

[27] C. L. Weber, P. Jaramillo, J. Marriott, and C. Samaras, "Life cycle assessment and grid electricity: what do we know and what can we know?," Environmental science \& technology, vol. 44, pp. 1895-1901, 2010.

[28] M. A. Curran, M. Mann, and G. Norris, "The international workshop on electricity data for life cycle inventories," pp. 853-862, 2005.

[29] P. Blum, G. Campillo, W. Münch, and T. Kölbel, "CO2 savings of ground source heat pump systems - A regional analysis," Renewable Energy, vol. 35, pp. 122-127, 1// 2010.

[30] S. Soimakallio, J. Kiviluoma, and L. Saikku, "The complexity and challenges of determining GHG (greenhouse gas) emissions from grid electricity consumption and conservation in LCA (life cycle assessment) - A methodological review," Energy, vol. 36, pp. 6705-13, 12/ 2011.

[31] R. Itten, R. Frischknecht, and M. Stucki, "Life cycle inventories of electricity mixes and grid," ESU-services Ltd., Uster, 2012.

[32] O. Jolliet, M. Saadé, P. Crettaz, and S. Shaked, Analyse du cycle de vie: comprendre et réaliser un écobilan vol. 23: PPUR Presses polytechniques, 2010.

[33] i.e.s.o. Power to Ontario On Demand, Available: http://ieso-public.sharepoint.com/Pages/PowerData/default.aspx

[34] d. magazine, Accessed on January, Available: http://www.ddmagazine.com/2699-Google-vers-100denergie-renouvelable.html 